has lately become a subject of much attention. The chapter on sampling contains an extensive review of the methods available and, although no experimental details are given, the comprehensive list of references will help the reader to overcome this.

Success in coping with any analytical problem by gas chromatography is dependont on good column technology, and appropriately one of the longest chapters is devoted to this. Column efficiency and the theory of column processes are discussed in the minimum necessary detail, and among other related matters a particularly useful appraisal of the role of the solid support is given. Considerable attention is also given to the subject of detection systems for which, in the course of time, almost every physical method of measurement has been employed. Here the obvious pitfall of attempting too much has been avoided without the author confining himself only to the commonly available forms. One would have thought, however, that the electron capture detector could justifiably have been considered at greater length.

Electronic integration systems are playing an increasingly important part in the interpretation of analytical data. Most chromatographers will therefore find interest in the chapter on applications of digital clectronic systems where the general philosophy of integration is discussed, but surely this should follow the succeeding chapters on interpretation of analytical data.

Another subject of singular importance to the chromatographer is peak identification which is dealt with in two chapters, one on ancillary systems (for example, in line use of spectrometers), and the other on reaction systems which involve chemical techniques. A final chapter deals with automatic process gas chromatography.

Although expensive, this is a book which will be particularly appreciated by those to whom gas chromatography is just another analytical technique with which they have become familiar.

E. A. WAL.KER

\section{MAPS OF THE ANTARCTIC}

\section{Glaciers of the Antarctic}

By John Mercer. Pp. $10+4$ plates. (Antarctic Map Folio Series, Folio 7.) (New York: American Geographical Society, 1968.) n.p.

\section{The Antarctic Atmosphere}

Climatology of the Surface Environment. Compiled by the US National Records Center and W. S. Weyant. Pp. 4+13 plates. (Antarctic Map Folio Series, Folio 8.) (New York: American Geographical Society, 1968.) n.p. THERE are to be about twenty folios in this series, summarizing present knowledge of the Antarctic in so far as it is suitable for presentation in atlas form. The series as a whole was introduced to the readers of Nature by G. de Q. Robin $(208,439 ; 1965)$ and his general remarks still apply. The criticism of these two folios is that advantage has not been taken of the atlas form-or much of the information is unsuitable for presentation on distributional maps. Folio 7 consists of a descriptive review, after the manner of a scientific paper, with 155 references. Negligible information is given on the maps; on one sheet you will find maps of several sub-Antarctic islands each at a different and irrational scale (the scale for plate 1 is wrong). What is it about the occurrence of a glacier which makes it useful to plot the geographical distribution? Surely it will be better to consider the fundamental conditions which give rise to the occurrence of glaciers--wind, temperature, and precipitation.

This criticism is to a certain extent answered by folio 8 which in addition to the parameters already named considers the temperature/wind relation, cyclone tracks, blowing snow, and cloudiness. I was disappointed to find only three maps: a striking picture of mean annual temperature, mean eloudiness, and an artistic impression of cyclone tracks. I am aware that there is some danger in drawing isolines through a pattern of observing stations which are too widely spaced, but this is largely a matter of choosing an appropriate contour interval and choosing a reasonable scale for the map, which should not attempt to give too much detail. Surely if mean parameters may be plotted, their variability may be plotted also, and if it is recognized that an atlas is probably for the use of a non-specialist in the discipline considered, then I believe that sketches, such as the cyclone tracks, are valuable and justified.

For each continental station, some attempt has been made to record the period of years to which the observations relate, but unhappily this has not been extended to the large number of sub-Antarctic stations extending as far as $40^{\circ} \mathrm{N}$. This vital climatological statistic, so easily included at the time of compilation, will be beyond the reach of the climatologist using this atlas in 25 years' time and having his more recent records for comparison.

The series as a whole will inevitably be compared with the Soviet Atlas Antarktiki (Moscow: Glavnoye Upravleniye Geodezii i Kartografi, 1966) which, with the same subject matter, makes a minimum use of histograms and wind-roses, and a maximum visual impression by the use of striking colouring for a large number of small-scale distributional maps.

S. Evans

\section{OBITUARIES}

\section{Anthony Richard Philpotts}

Tony Philpotts, who died in May, aged 47, was a spectroscopist who made some very important contributions to industrial ehemistry.

After graduation from Cambridge in 1942 he worked with Dr G. B. B. M. (now Sir Gordon) Sutherland in the physical chemical laboratories on war problems, notably trying to find the composition of enemy aviation fuel, using infrared absorption spectroscopy which was still undeveloped for analysis.

In 1945 Philpotts joined the central research department of the Distillers Company Ltd at Epsom, where he applied spectroscopic techniques to problems ranging from the structure of polymers of formaldehyde and acetaldehyde to the measurement of absolute intensities of absorption bands. $\mathrm{He}$ developed a profound knowledge of the relationships between the structure of a compound and its infrared spectrum which he applied to analytical problems. One striking success was the development of a method for analysis of the oxidation products of cumene, a step which proved essential for the successful development and operation of the Distillers cumene/phenol process; phenol is produced by the oxidation of cumene in controlled conditions, followed by cleavage of the resulting hydroperoxide to give phenol and acetone. In 1960 Philpotts took charge of all the analytical research and services at Epsom.

Philpotts' published work is not extensive because most of his efforts were devoted to solving problems in which industrial security considerations precluded publication. He was, however, one of the first to appreciate the effects of slit-width on absorption measurements and his paper in 1951 pioncered the measurement of absolute intensity.

The use of infrared spectroscopy for structural analysis of organic compounds was his special interest. He published a valuable paper on spectra of peroxides but his main work on the correlation between absorption frequencios and structure of unsaturated compounds containing ehlorine or oxygen has not appeared in print. It 
was, however, reported at conferences and has been acknowledged in the literature.

Moro recently he pioneered the use of analytical techniques in combination. He developed and reportod various techniques for recording spectra of gas chromatography fractions and he had now techniques of this type under development at the time of his death.

\section{University News}

The following appointments have been made in the University of Edinburgh: Mr G. B. Oddie to the Robert Adam chair of architecture; Dr G. B. Wilson to the chair of architectural science; Dr A. H. Cook to the chair of geophysics; Dr F. Alexander to a personal chair in veterinary pharmacology.

Mr Stanley L. Wright, principal of Edinburgh College of Art, has been appointed to the newly established chair of applied design at Heriot-Watt University.

The following appointments have been made at the University of Newcastle upon Tyne: Pro-vicechancellor, Professor N. J. Petch, William Cochrane professor of metallurgy, head of the Department of Metallurgy and honorary director of the Science Research Council Unit on Brittle Fracture; Dean of Medicine, Professor G. A. Smart, professor of medicine. Dr N. C. Freeman has been appointed to the second chair in mathematics.

Professor A. V. Johnson, University of Nottingham, has been appointed professor of chemistry at the University of Sussex.

The Duke of Abercorn is to be the first chancellor of the new University of Ulster.

Dr R. P. Spencer has been promoted to professor of nuclear medicine and Dr A. Bouhuys has been promoted to professor of medicine and epidemiology in the Yale University School of Medicine.

\section{Announcements}

Sir Barnes Wallis has been awarded the Albert Medal of the Royal Society of Arts for his contribution to the development of aeronautical science and engineering.

Dr H. D. Turner, assistant registrar in the University of Sheffield, has been appointed to succeed Sir Norman Wright as secretary of the British Association for the Advancement of Science. Mr R. P. Saville has been appointed assistant secretary.

The following elections were made at the Anniversary Meeting of the Linnean Society of London: president, Professor A. R. Clapham; treasurer, The Earl of Granbrook; secretaries, Mr J. P. M. Brenan (botany), Dr P. H. Greenwood (zoology), Dr Doris M. Kermack (editorial); members of council, Professor O. M. B. Bulamn, Professor A. J. E. Cave, Mr F. R. Goodenough, Professor V. H. Heywood, Professor D. H. Valentine; foreign members, Professor A. Fernandes (Portugal), Dr F. Stafleu (Holland). Dr K. L. Alvin, The Earl of Cranbrook, Dr C. T. Prime and Dr M. E. Varley were appointed vice-presidents. Linnean gold medals were presented to Professor Alastair Graham and Professor 'Thomas Maxwell Harris and the H. H. Bloomer award for an amateur naturalist was presented to the Hon. Miriam Rothschild.

The trustees of the Lady Tata Memorial Fund for research in leukaemia and allied disorders have made the following awards for 1968-69: Fellowship, Miss E. Davidson (University of Edinburgh); Scholarships, Dr V. Balazs (University of Leiden), Dr M. M. Fröhlich (Leiden University), Dr R. Hancock (Swiss Institute for Experimental Cancer Research), Dr O. Mach (Institute of Haematology and Blood Transfusion, Prague), Miss A. M. Tomkys (ARC Institute of Animal Physiology, Babraham), Dr P. Stryckmans (Institut Jules Bordet, Brusscls); Expenses grant, Dr D. Viza (IIôpital SaintLouis, Paris).

The Smithsonian Institution has awarded visiting research associateships to the following: Dr K. Apparao (Tata Institute of Fundamental Research, Bombay); Dr Philippa Black (Harvard University); Dr V. Buchwald (Arizona State University); Dr W. Cernohorsky (Emperor Gold Mining Company, Fiji); Dr E. R. de la Sota (La Plata University); Dr D. M. Devaney (Bernice P. Bishop Museum, Honolulu); Dr L. J. Hickey (Princeton University); Professor H. L. Li (University of Pennsylvania); Mr P. Malone (Case Western Reserve University); Dr B. Runnegar (University of New England, Armidale).

Applications are invited by Schering Chemicals Ltd, Berlin, for the Schoeller-Junkmann-Preiss 1969 which is worth 15,000 DM. Applicants, who should be less than 40 years of age and permanently resident in Europe, should submit unpublished manuseripts dealing with work in endocrinology (excluding studies of diabetes mellitus) before November 15 to Professor J. Zander, Direktor der Universitäts-Frauenklinik, 69 Heidelberg, Voss-Strasse 9, Germany.

The Australian Academy of Science invites applications for the Selby Fellowship from graduates in any branch of physical or biological science who hold a PhD degree or have equivalent status and experience and who wish to work for one year in Australia. Candidates should state the nature of the research they wish to undertake and the university department or research institution preferred. Further information is available from the Executive Secretary, Australian Academy of Science, Gordon Street, Canberra City, ACT 2601, Australia.

\section{Meetings}

July 21-26, Animal Reproduction and Artificial Insemination, Paris (Maison de la Chimie, 28 rue St Dominique, Paris 7).

August 18-23, Thermal Analysis, Worcester, Massachusetts (Dr C. B. Murphy, Xerox Corporation, PO Box 1540, Rochester, New York, USA).

August 25-31, 24th International Congress of Physiological Sciences, Washington, DC (Secretariat, 9650 Rockville Pike, Bethesda, Maryland 20014, USA).

August 26-28, Haemophilia, Montreal (World Federation of Hemophilia, 122 Arlington Avenue, Montrcal 6, Quebec, Canada).

August 26-31, Land Evaluation, Canberra (Mr G. A. Stewart, Division of Land Research, CSIRO, PO Box 109, Canberra City, ACT, Australia).

September 1-3, Regulation of Food and Water Intake, Haverford, Pennsylvania (Dr A. N. Epstein, Leidy Laboratory of Biology, University of Pennsylvania, Philadelphia, Pennsylvania 19104, USA).

September 1-7, European Regional Conference on Electron Microscopy, Rome (Dr Steve Bocciarelli, Istituto Superiore di Saniti, Viale Regina Elena 299, 00161 Rome, Italy).

September 2-6, Fermentation Advances in the Light of Recent Theoretical Progress in Microbiology, Biochemistry and Engineering, New Brunswick (Third International Fermentation Symposium, Rutgers, the State University, New Brunswick, Now Jersey, USA).

September 3-6, Macromolecular Chemistry, Toronto (Organizing Committee, Box 932, Terminal A, Toronto, Canada). 